ordinary bulked commercial raw milk and the same milk pasteurized gave no detectable difference in growth-rate when fed to calves, rats or children. The effects not only of pasteurization but also of sterilization, condensing and drying, on the nutritive value of milk were studied, and those of pasteurization were shown to be negligible. It was found, however, that ordinary daylight destroyed vitamin $\mathrm{C}$ in milk fairly rapidly. The new method of high-temperature. short-time pasteurization was thoroughly investigated and shown to be effective if carried out at $161^{\circ} \mathrm{F}$. for $15 \mathrm{sec}$. 'holding'. The phosphatase test for efficiency of pasteurization was devised. The length of time of survival of tubercle organisms in infected pastures and in dairy products made from infected milk was determined. The precursors, in the blood of the cow, of the milk constituents were studied and the effect of feeding thyroid gland or administering pure thyroxine to lactating cows was shown to be a rise both in milk yield and butterfat percentage. Taints in milk were examined for cause, and methods of prevention worked out. Some preliminary work was done on the problem of defective compositional quality in milk. Many other problems, ranging from the very practical question of the efficiency of bottlewashing machines to an academic inquiry (with potentially important industrial bearings) on the site in the animal body of the conversion of the plant pigment carotene to vitamin A, were investigated.

The outbreak of war in 1939 led to a diversion of effort to urgent problems of possible war-time significance. The better use in dairying of homeproduced feeding stuffs, the organisation of a national scheme for maintaining, and if possible improving, the keeping quality of milk to prevent any souring losses, emergency methods of cleansing dairy apparatus, the prevention of the serious effect in the cheesemaking industry of 'slow' starters, rheological methods for the assessment of cheese quality, the purification and crystallization of the enzyme, rennin, the use of iodinated proteins for increasing milk yields, the induction of an artificial lactation in a sterile or virgin heifer or in a barren cow by treatment of the animal with synthetic œstrogens-all these indicate a few only of the activities of the Institute staff during the War. Further, the serious fall in the compositional quality of milk which took place during the late winter months of the war years -and which is still with us-was carefully investigated. Arising out of this work is the more recent (1948) finding that certain British species of grass and of clover contain an active cestrogen, the identity of which is now being sought. A simple apparatus for determining whether or not a cow is 'on heat' was devised.

At the request of the Ministry of Agriculture, an experimental artificial insemination centre was established at the Institute in 1942. The lessons gained were of value when a nation-wide scheme for artificial insemination was launched in 1944. In 1949, 21,000 cows were inseminated artificially from Shinfield, while the total number for England and Wales was nearly 500,000 , about one seventh of the total dairy cow population.

The phenomenon of 'let-down' of milk in the cow, both in its physiological relationships and in its more practical bearings on milking technique and the design of milking machines, has been and is still being studied. The 'let-down' appears to result from the contraction of the myo-epithelial notwork surrounding the secreting alveolus, under the action of a hormone of the posterior pituitary gland. The hormone is liberated following either tactile stimulus of the teat or by some other sensory stimulus associated by the cow with milking. Further work on the biochemistry of milk formation, using the Warburg technique with gland slices and also radiotracers, has shown that one of the principal sources of mill fat is the circulating acetate in the blood of the ruminant. Bacteriophage has been shown to be responsible in several cheose-making factories for 'slow starter' difficulties, and successful methods for overcoming this trouble have been demonstrated to the staffs of these factories. The keeping quality of spray-dried milk has been markedly improved by a method devised during the War. Shortly after the War, a new antibiotic, nisin, was isolated from a culture of a lactic acid streptococcus. Nisin has since been demonstrated to have very promising in vivo potentialities against a number of diseases. It has been crystallized and its composition is being examined.

\section{PRODUCTION AND APPLICATION OF HIGH-INTENSITY X-RAY BEAMS}

A CONFERENCE organised by the X-ray Analysis Group of the Institute of Physics on "The Production and Application of High-Intensity X-ray Beams" was held in the Royal Institution during April 13-14.

Two quite distinct methods of approach to the problem of obtaining X-ray beams of high intensity were described at the conference. On one hand, there is the method worked out from 1927 onwards by the late Dr. A. Müller and developed practically in col: laboration with Mr. R. E. Clay. They used a comparatively large rectangular focus in conjunction with a rapidly rotating anode and, in this way, were able to achieve high power-loadings without damage to the target. The other method is to concentrate the electron beam into an exceedingly small region of the anode. In this way, high specific loading can be achieved with a small power input, and the brilliance of the point focus is considerable. As the heat flow from a point occurs in all directions (radially into the target volume), the dissipation of heat is much more rapid than in the case of the large focus treated by Müller (and, later, by Oosterkamp), where the heat flow is effectively linear (normal to the surface of the target only).

So marked is this effect that, as was stated by Dr. W. Ehrenberg and Mr. W. E. Spear at the conference, there is now little advantage to be gained in rotating the target. These workers gave a most elegant solution of the problem in electron optics of achieving a point focus. The essential feature of their generator is the fact that filament, grid (or focusing shield) and the outer tube are all at the same potential. In the conventional $\mathrm{X}$-ray tube, the outer casing is earthed, and is at the same potential as the earthed anode. In Ehrenberg and Spear's design, the filament, grid and outer casing are all earthed, and the insulated anode is maintained at high potential. With this very simple arrangement, they obtain a focus the diameter of which is of the order of $0.04 \mathrm{~mm}$., and are able to use a specific loading of $12 \mathrm{~kW} . / \mathrm{mm} .^{2}$ for long periods without injuring the target. 
A more elaborate micro-focus $\mathrm{X}$-ray tube was described and demonstrated by Mr. R. Witty and Mr. P. Wood. A biased electron gun forms a first image of dimensions $1 \mathrm{~mm}$. $\times 0.1 \mathrm{~mm}$, and an electromagnetic lens is used to reduce this to $0.1 \mathrm{~mm}$. $\times 0.01 \mathrm{~mm}$. A specific loading of $50 \mathrm{~kW} . / \mathrm{mm} .{ }^{2}$ has been achieved on a focus of size $0.05 \mathrm{~mm} . \times 0.01 \mathrm{~mm}$., but the target was damaged after an hour of working by this method.

The moving-anode type of uube has been brought to a high level of convenience by Dr. A. Taylor. He described two different designs for a $5-\mathrm{kW}$. generator, one of which employs only static vacuum seals. The other assembly is very easily dismantled and allows the anode to be changed in less than two minutes. Dr. J. S. Woldringh gave particulars of the five rotating-target tubes which exist in Holland and which follow British practice closely.

The usual practice with rotating-anode tubes is to use a line focus and to take off the radiation at a small angle in order to foreshorten the line into a rough square. Dr. D. P. Riley argued that there are limits to this method of obtaining a fine X-ray source. From Müller's expression for a true focus of large dimensions, it follows that for a given generator working under given optimum and safe conditions, there is a fixed relation between the length and width of the focus. Once the width is defined by the degree of focusing used, the 'safe' length can be derived and this length varies directly with the power input. Thus, a combination of fine focusing and high power necessitates a very long focus which would be difficult to foreshorten sufficiently. The situation, however, would be expected to be qualitatively different once a sufficiently fine line focus were obtained, as, in this case, the heat flow would be approximately cylindrical instead of linear, and higher loadings than those permitted by the Müller formula could be used. These conditions have probably now been reached in the modified 50-kW. generator. An even line focus of width $0.1 \mathrm{~mm}$. has been obtained without the necessity of biasing by using a tungsten strip filament.

Mr. J. S. Thorp has derived fine line foci by using bias but complained of a marked banded structure in the equipotential case. He uses a tungsten wire filament of diameter comparable to the size of his cathode tip, which is much smaller than that employed in the above case, which may explain the difference between his and Dr. Riley's results.

While agreeing that a numerical comparison of the relative performance of different tubes is needed, the conference failed to produce a definition of a 'factor of excellence' of an X-ray generator.

The question of collimation and the production of monochromatic beams was next considered. Dr. I. MacArthur described the preparation of stop slits from a lithium-bismuth alloy by pressing it around t-mm. diameter steel pins. He also diseussed the limitations of very fine capillary slits made from lead glass and showed that secondary diffraction effects make them unsuitable for use at very low angles of diffraction. The principle of the total reflexion of $\mathrm{X}$-rays from a smooth surface has been employed by Dr. Ehrenberg to make a focusing mirror of high resolution and great concentrating power. The great theoretical advantage of the method is, however, diminished by virtue of the roughness to $X$-rays of even the best optical flat. Dr. P. M. de Wolff gave an account of Tiedema's method of obtaining large aluminium crystals in the form of lamellæ with any desired orientation. Johannsen-type monochromator crystals can be obtained in this way without the necessity of grinding. Dr. de Wolff himself employs quartz as his monochromator crystal and showed that a strip of it can be bent into a great variety of curves by using four loads. Such monochromators have been used with multiple focusing cameras for some time in Delft and give very high resolving power and gain of intensity. Mr. P. Gay has extended the work of Hirsch and Kellar on asymmetric Bragg reflexion from obliquely ground crystals and advised the use of lithium fluoride where maximum intensity is sought and of calcite if maximum resolution is the aim. Lithium fluoride has also been used, as Dr. W. H. Taylor reported, by Dr. H. E. Hargreaves in a $30-\mathrm{mm}$. focusing monochromator to separate the $K \alpha_{1}$ component of iron radiation. This technique, also used in France, has allowed him to obtain very sharp and clear powder photographs of copper-ironnickel alloys.

The conference then heard a number of very short communications on different techniques useful in connexion with X-ray analysis. M. G. Fournet described the use of two bent-crystal monochromators in series to suppress parasitic scattering due to crystal imperfections, and Compton and thermal scattering. $\mathrm{He}$ has recorded a diffraction band at $240 \mathrm{~A}$. from egg-yolk with this apparatus. Mr. H. Smith gave details of his method of producing thin sheets of beryllium by bombarding the metal with electrons under high vacuum. Foil only $0.1 \mathrm{~mm}$. thick has been produced and used for X-ray tube windows. Mr. E. G. Steward showed how simple devices could be attached to standard cameras to allow work at moderately high or low temperatures. Dr. W. J. Oosterkamp gave a stimulating analysis of the possibility of using radioactive isotopes as a source of monochromatic $K$-radiation. $\mathrm{He}$ concluded that an isotope with a half-life of one day would, in this respect, be roughly equivalent to a stationary target tube. This short half-life made it an uncompetitive method. Dr. O. Lloyd Richards demonstrated how sprung models of close-packed structures can clearly illustrate the slight atomic rearrangements which take place in a metal under tension or on rolling.

The third session of the conference dealt with the application of high-intensity X-ray beams to research problems and ranged over a great variety of topics. In many studies, high intensity may be a great convenience but is not essential. It becomes essential when, for example, time-dependent processes of short duration are to be investigated or when the specimen is unstable or deteriorates with time. Few examples of the second class of problem were given at the conference, and it appears that, as yet, powerful tubes are being used mainly to save time in long exposures. This, in itself, if the gain is sufficient, makes it an economic matter to study systems which diffract X-rays only exceedingly weakly.

In the field of biological and colloid chemistry, there are many applications of this type, some of which were reported by Dr. D. P. Riley. The structure of oil-water-soap emulsions has been investigated with Dr. J. H. Schulman and Dr. T. S. MacRoberts. Droplet diameters up to $700 \mathrm{~A}$. have been measured and are in good agreement with values found by the light-scattering method and predicted on chemical grounds. With Dr. D. Herbert, preliminary figures for the dimensions of protein molecules (human hæmoglobin, egg albumin) have been derived from the diffraction patterns given by concentrated solutions. In the case of egg albumin, there is evidence 
of molecular association even in quite dilute solutions. In collaboration with Dr. G. Oster, it has been shown that gels and solutions of deoxyribonucleic acid (sodium salt) from thymus possess a pronounced micellar structure of a lattice type, which swells on dilution. In addition, there is evidence that the molecule itself can swell. The parent nucleoprotein also gives definite low- and medium-angle diffraction bands. Both substances are being further investigated because of their importance as constituents of living cells.

Another important field in which the use of highintensity sources is almost obligatory is that of the diffuse scattering of $\mathrm{X}$-rays by single crystals. Dr. P. G. Owston showed examples where, without monochromatic radiation, much fine detail was lost. The use of monochromators with a standard tube involves exposure times of several days, and each crystal has to be photographed in many different orientations. High-power tubes drastically reduce the time taken by such a survey. Further, when Geiger-Müller counters are used, the 'background' counts set a lower limit to the detectable intensity and to the accuracy with which weak scattering can be measured. A highintensity X-ray source is indispensable if this obstacle is to be surmounted. Dr. Owston also described researches involving the recording of very weak Bragg reflexions arising from the lack of spherical symmetry of electron clouds around atoms. Information on the position and state of bonding of hydrogen atoms might be obtainable in this way.

Mr. P. B. Hirsch contributed an account of a micro-beam technique applied to the study of coldworked metals. Back-reflexion photographs were taken of cold-rolled aluminium with a beam of diameter about 35 microns and different divergences. The diffraction patterns consist of 'spotty' rings, and from the number of spots the mean grain-size of particles within the metal can be determined. For heavily cold-worked aluminium, examined a year after rolling, this mean size is about 2 microns. As the spots on the diffraction rings are themselves broadened, it is concluded that the breadths of the diffraction lines obtained by the usual methods are partly due to the breadth of the small spots of which they are constituted. The breadths of the spots are explained in terms of distortion and shape of the particles. It was found that this broadening decreases with time after rolling, as does the particle size.

Dr. I. MacArthur presented a great number of comparative data on homologous series of long-chain compounds under varying conditions. Discontinuous and continuous transitions were both observed as one varied the chain-length, nature and position of the polar group and temperature. For a full interpretation of the many effects, account must be taken of other physical chemical data. The X-ray method, used in isolation, loses much of its power in such cases.

It was found during the investigation of the properties of the parallel-beam concentration monochromator that a surface layer of disordered material is formed when the crystal is ground. Mr. P. Gay has studied the surfaces of abraded crystals with the $\mathrm{X}$-ray and electron diffraction techniques and correlated the results with the intensity of reflexion from the same crystals.

The conference served a useful purpose in bringing together people who had obviously been working along similar lines, but in isolation, and showed others that very powerful techniques are now available for their particular X-ray diffraction problems. Little experience has yet been had with the high-intensity beams ; but, in conjunction with sensitive detectors, such as Geiger-Müller counters, they cannot fail to open up new avenues of structural exploration of ordered matter. As Prof. J. D. Bernal said, thought now needs to be given to new types of camera for use with the new tubes in order that they be used most effectively.

On this occasion, an agreeable and stimulating evening lecture was given by Prof. A. Guinier, of Paris, who took as his subject "The Role of High. Intensity Beams in the Progress of X-ray Analysis".

$$
\text { D. P. RILEY }
$$

\section{CORRELATION OF ELECTRO- PHORETIC STUDIES AND OTHER FACTORS IN THE SYNDROME OF SECONDARY SHOCK}

\author{
BY PROF. DAN H. MOORE \\ AND \\ DR. C. L. FOX
}

College of Physicians and Surgeons, Columbia University, and the U.S. Office of Naval Research, London

$\mathbf{N}$

UMEROUS factors are involved in the com. plicated syndrome of shock. Blalock ${ }^{1}$, Nickerson $^{2}$, Ashworth, Jester and Lloyd ${ }^{3}$ and others ${ }^{4}$ have shown that the loss in circulating blood volume could be accounted for by the gain in weight by traumatized area. From these observations many investigators have concluded that the symptoms observed in shock result from this loss of blood.

On the other hand, in experiments dealing with tourniquet shock in dogs, Scotts has shown that there is no difference in the quantity of fluid lost into the site of injury of dogs whioh die and of those which spontaneously recover. Moreover, Wang et al. ${ }^{6}$ have produced quantitative data which show that in hæmorrhage the residual blood volume at 50 per cent mortality in dogs is 59 c.c. per $\mathrm{kgm}$. of bodyweight, whereas in trauma 50 per cent mortality occurs when the residual blood is 73 c.c. per $\mathrm{kgm}$. of body-weight. The shift of potassium from the traumatized area into the blood and the loss of sodium from the blood as well as shifts in other ions have also been demonstrated to be of importance ${ }^{2-10}$.

Other substances from the traumatized area, such as tissue factors ${ }^{11}$ and enzymes, have also been postulated. In the studies reported here quantitative and qualitative analyses have been made of the shift of proteins and other substances from the circulatory bed into the traumatized areas, and from the traumatized areas into the blood.

Tissues of Swiss albino mice were traumatized by the method of Rosenthal ${ }^{12}$, which here consisted of a tight tourniquet on on $\theta$ of the hind-legs for two hours, followed by release. The degree of shock which followed was found to be dependent upon the environmental temperature and humidity. When the ex. periments were carried out in summer, the degree of shock and the fatalities were decidedly greater than in winter. At a temperature of $20^{\circ} \mathrm{C}$. and humidity of 50 per cent, or at a temperature of $32^{\circ}-35^{\circ} \mathrm{C}$. and a humidity of 5 per cent, none of the animals died within six hours. At a temperature of $32^{\circ}-35^{\circ} \mathrm{C}$. and a humidity of 75 per cent or more the mortality was 